\title{
Cognitive behaviour therapy for fatigued cancer survivors: long-term follow-up
}

\author{
MFM Gielissen ${ }^{*, 1}$, CAHHVM Verhagen² and G Bleijenberg' \\ 'Expert Centre Chronic Fatigue Nijmegen, Radboud University Nijmegen Medical Centre, Nijmegen 6500 HB, The Netherlands; ${ }^{2}$ Department of Medical \\ Oncology, Radboud University Nijmegen Medical Centre, Nijmegen 6500 HB, The Netherlands
}

\begin{abstract}
An earlier randomised-controlled trial demonstrated the positive effects of cognitive behaviour therapy (CBT), especially designed for fatigued cancer survivors in reducing fatigue, functional impairments and psychological distress. In the current prospective study, we were able to examine the long-term effect of CBT in patients who completed the therapy. Predictors of fatigue severity at follow-up were exploratory investigated. Sixty-eight patients who completed CBT were assessed at pretreatment, post-treatment and at follow-up (mean follow-up 1.9 years (s.d. I.0), range: I-4 years). To analyse possible predictors of treatment outcome a linear regression (enter) was carried out. Improvements on fatigue severity, functional impairment and psychological distress after CBT appeared to remain stable during a follow-up period. Patients who were not fatigued anymore at follow-up were not different from a reference group of non-fatigued cancer survivors. The explorative regression analysis showed that fatigue severity, psychological distress and somatic attributions at pretreatment contributed to persistent fatigue severity at follow-up. Cognitive behaviour therapy, especially designed for post-cancer fatigue, is successful in reducing fatigue and functional impairment in cancer survivors. Moreover, these positive effects were maintained at about 2 years after finishing CBT.
\end{abstract}

British Journal of Cancer (2007) 97, 612-618. doi:10.1038/sj.bjc.6603899 www.bjcancer.com

Published online 24 July 2007

(c) 2007 Cancer Research UK

Keywords: cancer survivors; cognitive behaviour therapy; fatigue; intervention; long-term effect; post-cancer fatigue

Fatigue is a common and distressing side effect of cancer treatment (Servaes et al, 2002b; Prue et al, 2006). Unfortunately, fatigue persists in patients for even years after completion of curative treatment. At least a quarter of the cancer survivors suffer from post-cancer fatigue, with profound effects on quality of life (Servaes et al, 2002b, in press; Hjermstad et al, 2005; Sugawara et al, 2005; Bower et al, 2006; Prue et al, 2006).

Although research on post-cancer fatigue has increased in the last decennia, there are only a few randomised-controlled trials (RCTs) investigating the management of post-cancer fatigue. Until now, six RCTs have investigated the effect of an intervention on fatigue, measured as a primary or secondary outcome. Two were pilot studies and found no effect on fatigue (Basen-Engquist et al, 2006; Culos-Reed et al, 2006). No effect was found investigating a lifestyle physical activity intervention (Basen-Engquist et al, 2006) and the second study found no effect of yoga (Culos-Reed et al, 2006). Two studies investigated the effect of exercise in cancer survivors. Both studies used fatigue as a secondary outcome and showed beneficial effects (Courneya et al, 2003; Pinto et al, 2005). The fifth study found that acupuncture was a more effective method to improve fatigue compared with acupressure or sham acupressure (Molassiotis et al, in press). None of these RCTs includes follow-up assessments. In the last RCT cognitive behaviour therapy (CBT), especially designed for post-cancer fatigue, appeared to be highly effective (Gielissen et al, 2006). The rationale of this intervention was based on the model of

*Correspondence: Dr M Gielissen; E-mail: m.gielissen@nkcv.umcn.nl Received 29 January 2007; revised II June 2007; accepted 28 June 2007; published online 24 July 2007 precipitating and perpetuating factors. Fatigue seems to be elicited during the treatment phase, but later on there is no clear relationship between persistent fatigue and initial disease and cancer treatment variables (Servaes et al, 2002b; Hjermstad et al, 2005; Ng et al, 2005; Prue et al, 2006; Young and White, 2006). The assumption is that the cancer itself and/or the cancer treatment may have triggered fatigue (precipitating factors), but other factors are responsible for persistence of fatigue complaints (perpetuating factors). Cognitive behaviour therapy for post-cancer fatigue is focused on these perpetuating factors. The RCT consisted of two conditions, the intervention condition (6 months of CBT) and waiting list condition (6 months). Patients in the intervention condition reported a clinically relevant decrease compared to patients in the waiting list condition in fatigue severity, functional impairment and psychological distress. Patients in the waiting list condition were informed beforehand that, if desired, they could start therapy directly after the waiting period of 6 months.

In this current study, the long-term effect of CBT will be investigated in patients who were involved in this former study and received CBT, including patients in the intervention condition and patients who had been treated after the 6-month waiting list. Furthermore, we will exploratory investigate predictors of fatigue severity at follow-up.

\section{METHODS}

\section{Sample}

Between December 2001 and September 2004, six departments of the Radboud University Nijmegen Medical Centre participated in the recruitment of patients for this study. Cancer survivors who 
experienced severe fatigue (score of 35 or higher on the Checklist Individual Strength, fatigue subscale) were recruited from the outpatient clinics of medical oncology, urology, surgery, orthopaedic, haematology and gynaecology. During follow-up visits in the hospital fatigued survivors were screened by their physician on clinically relevant systematic diseases (eg, malnutrition, haemoglobin level, presence of hypothyroidism and other physical comorbidities). If a physician was certain that the fatigue had no somatic cause, the patient was invited to participate. Patients completed curative treatment for cancer at least 1 year ago and had a minimal age at disease onset of 18 years. At time of participation patients had no evidence of disease recurrence and patients were not older than 65 years. Patients with current psychological or psychiatric treatment were excluded. The ethics committee of the hospital approved the study.

\section{Intervention}

Cognitive behaviour therapy was focused on six perpetuating factors of post-cancer fatigue, which were based on existing literature and experience in clinical practice. They involve (1) insufficient coping with the experience of cancer, (2) fear of disease recurrence (Servaes et al, 2003; Young and White, 2006), (3) dysfunctional cognitions concerning fatigue (Broeckel et al, 1998; Servaes et al, 2002c), (4) dysregulation of sleep (Servaes et al, 2002b; Prue et al, 2006), (5) dysregulation of activity (Servaes et al, 2002a; Prue et al, 2006; Young and White, 2006) and (6) low social support and negative social interactions (Servaes et al, 2002c).

Each perpetuating factor became a module in the therapy protocol. Because of the existence of large differences within the group of fatigued cancer survivors (Servaes et al, 2002a), therapy was adapted to each individual. To determine which modules were necessary, each perpetuating factor was measured with specific questionnaires. If a patient scored problematic on one of these questionnaire, the accessory module became part of the treatment, resulting in an individualised treatment protocol per patient. It is important to realise that the therapy only varied in number of modules, but within each module the therapy is standardised. The number of sessions was determined by the number of used modules and by reaching the goal of the therapy.

Three therapists with previous CBT experience in patients with chronic fatigue treated patients who started directly with CBT as well as patients who started CBT after the waiting list period. For a more detailed description of the intervention see Gielissen et al (2006) (see Appendix A).

\section{Assessment}

Patients were asked to complete questionnaires at the Expert Centre Chronic Fatigue of the Radboud University Nijmegen Medical Centre, pretreatment and post-treatment. Additionally, a package of questionnaires was sent by mail to all patients 6 months after the last patient finished CBT.

Outcome measures Fatigue severity was measured by the fatigue severity subscale of the checklist individual strength (CIS) (Vercoulen et al, 1994; Beurskens et al, 2000; Dittner et al, 2004). The questionnaire has been used in cancer survivors (Servaes et al, 2002a, c, 2003, in press; Gielissen et al, 2006), showed good reliability, discriminative validity and sensitivity to change (Beurskens et al, 2000; Prins et al, 2001; Stulemeijer et al, 2005; Gielissen et al, 2006).

Functional impairment was measured by the sickness impact profile-8 (SIP-8). This widely used measure has good reliability and content validity (Bergner et al, 1981; Jacobs et al, 1990).

Psychological distress was measured by the symptom check list 90, which has good reliability and discriminating validity (Arindell and Ettema, 1986; Derogatis, 1994).
Perpetuating factors Coping with the experience of cancer was measured with the Dutch version of the Impact of Event Scale, which measures the extent to which a subject is currently occupied with the coping process after a major event (in this study the diagnose and treatment for cancer) (Brom and Kleber, 1985; Creamer et al, 2003; van der Ploeg et al, 2004).

Fear of disease recurrence was measured by two items of the Cancer Acceptance Scale (CAS) (Servaes et al, 2003).

Cognitions related to fatigue. Self-efficacy was measured with the Self-Efficacy Scale (Vercoulen et al, 1998; Prins et al, 2001; Servaes et al, 2002c, 2003) and somatic related attributions with regard to fatigue complaints were measured with the Causal Attribution List (CAL) (Servaes et al, 2002c).

Sleep disturbances was measured with the sleep/rest subscale of the SIP-8, and the insomnia subscale of the Quality of Life Questionnaire-C30 (QLQ-C30) (Aaronson et al, 1993).

Physical activity was measured with the physical functioning and role functioning subscale of the QLQ-C30. Furthermore, physical activity was measured with the subscales home management, work and recreation and pastimes from the SIP.

Social functioning was measured with the van Sonderen Social Support Inventory (SSL) (van Sonderen, 1993).

\section{Statistical analysis}

Data analyses were performed using SPSS (version 12.1). Independent samples $t$-test and $\chi^{2}$-squared tests were performed testing differences between the intervention condition and the waiting list condition.

In the current study, the data collected at the end of the 6-month waiting period were used as pretreatment measurements. Comparison of the results of the pretreatment, post-treatment and follow-up assessments were carried out by GLM repeated measures analysis. Furthermore, GLM multivariate analysis was performed testing the differences between different follow-up periods and with a reference group. In a previous study of our research group 93 non-fatigued breast cancer patients were identified and used in this study as reference group (CIS $<35$; mean age, 46.4 years; s.d. =6.3; Servaes et al, 2002c).

Mann-Whitney $U$-tests were used testing the differences between patient who did not accept CBT after the 6-month waiting list period and patients who completed CBT.

McNemar tests were used to analyse the differences between the proportions of patients who did not meet the criteria for severe fatigue (CIS-fatigue $<35$ ) anymore at post-treatment and follow-up.

To analyse possible predictors of treatment effects a linear regression (enter) was carried out, with fatigue severity at the last follow-up assessment as dependent variable. Pearson correlations between fatigue severity at follow-up and the six perpetuating factors were used as preparatory analyses to examine the contribution of these factors to fatigue severity. Those measures that correlated significant with the fatigue severity at follow-up were used as independent variables in the logistic regression analyses. Correlations between the six perpetuating factors were tested on multicollinearity $(r<0.9)$.

\section{RESULTS}

\section{Sample}

Figure 1 shows the trial profile. The controlled data are described in Gielissen et al (2006). In this current study, we used the pooled data of both conditions. In the intervention condition, 38 patients completed CBT of whom 36 had a follow-up assessment. Fortyfour patients completed the 6-month waiting list period and were offered CBT. Thirty-two patients accepted and completed the 


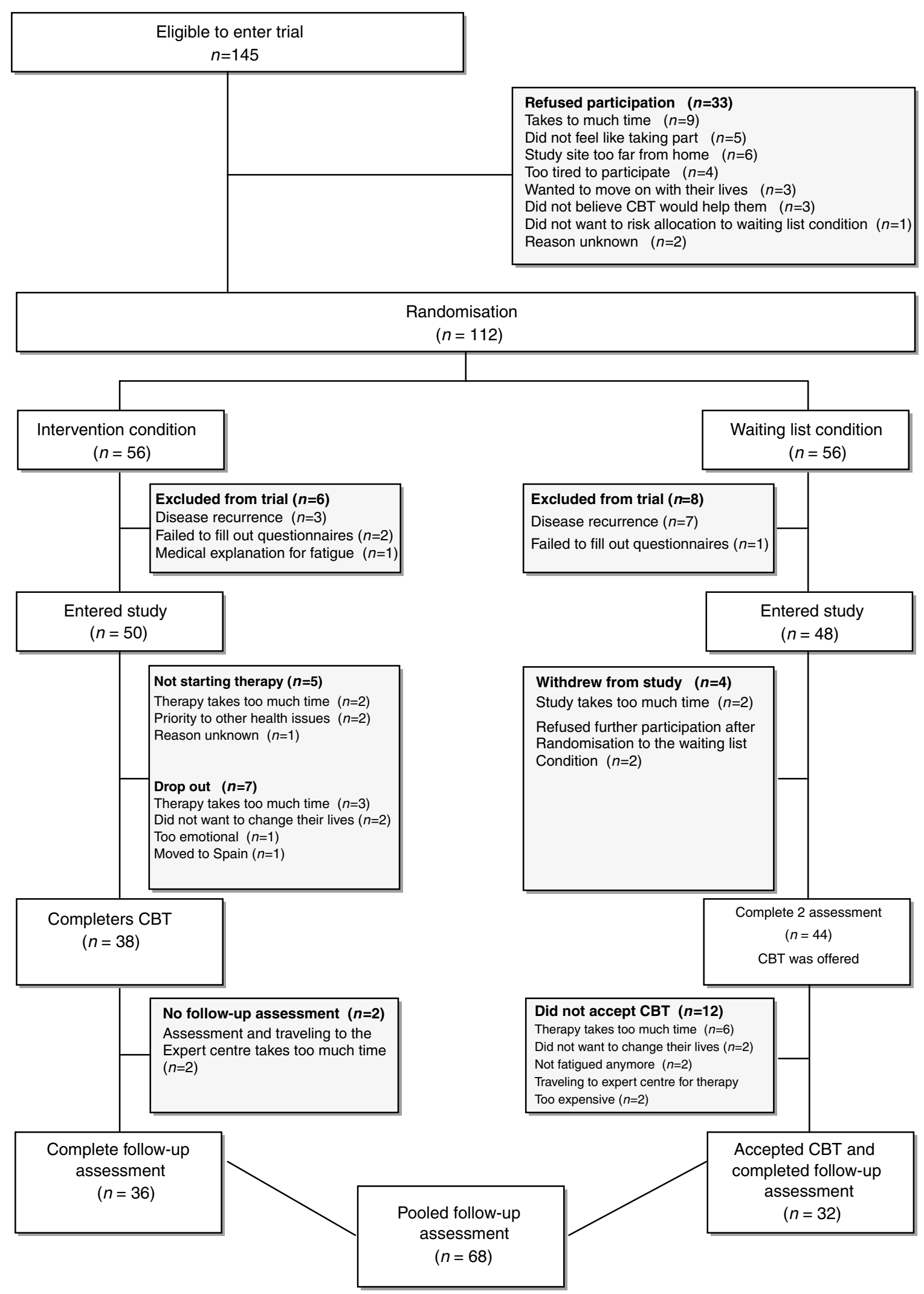

Figure I Trial profile.

therapy and the follow-up assessment. There were no significant differences between patients in the intervention condition and waiting list condition on demographic and medical characteristics
(Table 1). In addition, no significant differences were found on the outcome variables at pretreatment (fatigue severity $P=0.052$; functional impairment $P=0.210$; psychological distress $P=0.300$ ) 
and post-treatment (fatigue severity $P=0.582$; functional impairment 0.118 ; psychological distress $P=0.346)$. Furthermore, the number of CBT sessions in both conditions were equal (12.5 (4.7) vs 12.4 (4.6), $P=0.853$ ). Because no differences were found, the data of both conditions were pooled (Table 1).

Furthermore, we compared patients who did not accept CBT after the 6-month waiting list period $(n=12)$ with patients who completed CBT $(n=68)$. There were no differences in the pretreatment assessment on fatigue severity $(P=0.205)$, functional impairment $(P=0.925)$ and psychological distress $(P=0.671)$. Seven of the 12 patients who did not accept CBT after the waiting list period, completed the follow-up assessment.

\section{Long-term effect}

The mean length of time between completion of therapy and follow-up assessment was 1.9 years $($ s.d. $=1.0)$ with a range of 6 months to 4 years. The median was 2.0 years. The time interval between completion of therapy and follow-up assessment varied because patients entered the study at various times and started treatment at different moments.

Information about the outcome variables at the three assessments are listed in Table 2. Scores of fatigue severity, functional impairment and psychological distress significantly decreased at post-treatment and follow-up assessment compared with the pretreatment assessment. Additionally, the means on all outcome measures remained stable between post-treatment and follow-up.

Compared with the reference group, patients in this study were significantly more fatigued at follow-up assessment, but had the same level of functional impairment and psychological distress.

Table I Characteristics of study participants

\begin{tabular}{|c|c|c|c|}
\hline & $\begin{array}{c}\text { CBT } \\
(n=36)\end{array}$ & $\begin{array}{l}\text { Waiting list } \\
\quad(n=32)\end{array}$ & $\begin{array}{l}\text { Pooled group } \\
\quad(n=68)\end{array}$ \\
\hline Age (years) & $43.8(10.3)$ & $43.9(10.3)$ & $43.8(10.2)$ \\
\hline$M / F(n)$ & $19 / 17$ & $16 / 16$ & $35 / 33$ \\
\hline \multicolumn{4}{|l|}{ Cancer diagnosis \% (n) } \\
\hline Mamma carcinoma & $36 \%(13)$ & $25 \%(8)$ & $31 \%(2 I)$ \\
\hline Testicular cancer & $33 \%(12)$ & $25 \%(8)$ & $29 \%(20)$ \\
\hline Haematological cancer & $17 \%(6)$ & $16 \%(5)$ & $16 \%(11)$ \\
\hline Other solid tumours & $14 \%(5)$ & $34 \%(11)$ & $24 \%(16)$ \\
\hline \multicolumn{4}{|l|}{ Treatment type \% (n) } \\
\hline Surgery & $75 \%(27)$ & $81 \%(26)$ & $78 \%(53)$ \\
\hline Chemotherapy & $70 \%(24)$ & $84 \%(27)$ & $75 \%(5 I)$ \\
\hline Radiotherapy & $53 \%(19)$ & $44 \%(14)$ & $49 \%(33)$ \\
\hline $\begin{array}{l}\text { Duration of cancer treatment } \\
\text { (months) }\end{array}$ & $6.6(7.1)$ & $7.3(6.3)$ & $6.9(6.7)$ \\
\hline $\begin{array}{l}\text { Time since cancer treatment } \\
\text { (years) }\end{array}$ & $5.2(4.0)$ & $5.1(3.6)$ & $5.1(3.8)$ \\
\hline
\end{tabular}

$\mathrm{CBT}=$ cognitive behaviour therapy. Values are means (s.d.) unless stated otherwise. apercentages do not add up to $100 \%$ because more options are possible.
The follow-up period of patients who did not accept CBT $(n=7)$ was comparable with the follow-up period of patients who completed CBT (1.5 years (s.d. $=0.8), P=0.145$ ). Patients who did not accept CBT were significantly more fatigued, had more functional impairments and higher psychological distress at follow-up compared to patients who accepted CBT (Table 2).

Eighty-one percent $(n=55)$ of the patients did not meet the criteria of severe fatigue at post-treatment (CIS-fatigue $\geqslant 35$ ). At follow-up this percentage of non-fatigued patients was $71 \%$ $(n=48, P=0.118)$. Compared with the non-fatigued reference group (Table 2), the patients who were not fatigued after CBT $(n=48)$ had the same level of fatigue (19.9; s.d. $=8.4, P=0.842)$, the same level of functional impairment $(271.0$; s.d. $=292.7$, $P=0.476)$ and a significantly lower level of psychological distress (106.3; s.d. $=14.4, P=0.042)$.

\section{Short- $v s$ long-term follow-up}

As there is a considerable range in the duration of the follow-up, we investigated whether the treatment outcome differed between patients with a shorter and a longer follow-up period. Patients were divided into four groups: patients who completed CBT between 6 months and 1 year ago $(n=15)$, between 1 and 2 years ago $(n=21)$, between 2 and 3 years ago $(n=20)$, and between 3 and 4 years ago $(n=12)$. Post hoc analyses showed no significant differences on change scores (pretreatment scores -I- follow-up scores) between the four-follow-up period on fatigue severity, functional impairment and psychological distress (Table 3). Furthermore, correlations between time since CBT and fatigue severity $(r=-0.067, P=0.585)$, functional impairment $(r=216$, $P=0.077)$ and psychological distress $(r=141, P=0.251)$ were low and nonsignificant.

\section{Predictors}

Results of the preparatory analyses indicated that fatigue at followup was significantly correlated with fatigue severity (CIS-fatigue, $r=0.354, P=0.003$ ), psychological distress (SCL90-total, $r=0.398$, $P=0.001$ ), somatic related attributions (CAL, $r=0.293, P=0.015$ ) and insufficiency in social interactions (SSL-D, $r=0.316$, $P=0.009$ ) at pretreatment. These variables were used as independent variables in the linear regression analysis. Table 4 summarise the regression analysis. Somatic attributions contributed almost significantly $(P=0.050)$ to fatigue severity at follow-up. Furthermore, a trend was seen for pretreatment fatigue severity $(P=0.064)$ and psychological distress $(P=0.074)$.

\section{DISCUSSION}

The results of the present study indicate that the positive results of CBT especially designed for fatigued cancer survivors were maintained at follow-up. Fatigue severity, functional impairment and psychological distress remained stable in patients who

Table 2 Means and s.d. of CBT completers at pretreatment, post-treatment and follow-up, a reference group of non-fatigued cancer survivors and non-accepters of CBT at follow-up assessment

\begin{tabular}{|c|c|c|c|c|c|}
\hline $\mathbf{N}=\mathbf{6 8}$ & A pretreatment & B post-treatment & C follow-up & $\begin{array}{c}D \text { reference } \\
\text { values }(n=98)\end{array}$ & $\begin{array}{l}\text { Non-accepters CBT } \\
\text { at follow-up }(n=7)\end{array}$ \\
\hline Fatigue severity & $45.3(7.7)^{\mathrm{a}, \mathrm{b}, \mathrm{c}}$ & $24.3(10.9)^{c, d}$ & $26.9(\mid 3.1)^{c, d}$ & $19.6(8.4)^{a, b, d}$ & $40.3(14.8)^{\mathrm{e}}$ \\
\hline Functional impairment & $937.1(530.4)^{a, b, c}$ & $415.1(438.6)^{d}$ & $429.8(483.2)^{d}$ & $309.5(333.4)^{d}$ & $842.9(302.2)^{\mathrm{e}}$ \\
\hline Psychological well-being & $138.5(35.6)^{a, b, c}$ & | $13.6(25.5)^{d}$ & $119.3(37.1)^{d}$ & I $13.2(20.3)^{d}$ & $138.6(39.8)$ \\
\hline
\end{tabular}

$\mathrm{CBT}=$ cognitive behaviour therapy. ${ }^{a}$ Significantly different from post-treatment assessment $(P<0.05)$. ${ }^{b}$ Significantly different from the follow-up assessment $(P<0.05)$.

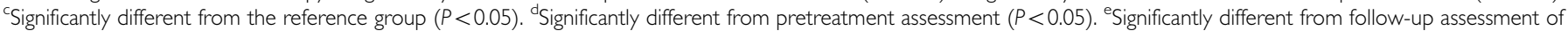
CBT-completers. 
Table 3 Change scores (pretreatment scores - /- follow-up scores) at different follow-up points

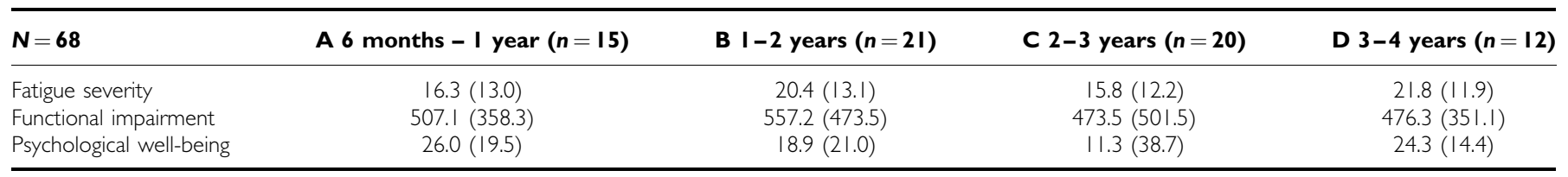

There were no significant differences on change scores between the four-follow-up periods.

Table 4 Linear regression (enter) to predict fatigue severity at follow-up

\begin{tabular}{lcc}
\hline & \multicolumn{2}{c}{$\begin{array}{c}\text { Dependent variable } \\
\text { CIS-fatigue at follow-up }\end{array}$} \\
\cline { 2 - 3 } $\begin{array}{l}\text { Independent variables } \\
\text { (pretreatment measurements) }\end{array}$ & $\boldsymbol{\beta}$ & $\boldsymbol{P}$-value \\
\hline Fatigue (CIS-fatigue) & 0.373 & 0.064 \\
Psychological distress (SCL90-total) & 0.087 & 0.074 \\
Dysfunctional cognitions (somatic-CAL) & 1.803 & 0.050 \\
Social insufficiency (SSL-D) & 0.086 & 0.422 \\
\hline
\end{tabular}

$\mathrm{CAL}=$ Causal Attribution List; $\mathrm{CIS}=$ checklist individual strength; $\mathrm{SCL}=$ symptom checklist; SSI = social support inventory. Adjusted $R^{2} 0.222$.

completed CBT after almost a mean follow-up period of 2 years. Furthermore, we could not find any difference between patients with a short- and a long-term follow-up. Therefore, even after 4 years the positive effect of CBT remained.

Patients who were allocated to the 6-month waiting list were offered CBT directly after the second assessment. Therefore, the long-term effect was investigated with an uncontrolled design. Nevertheless, patients who were recovered at follow-up were comparable with a reference group of non-fatigued cancer survivors. Additionally, we investigated a small group of patients who did not accept CBT after the waiting list period. These patients did not improve over time on fatigue severity, functional impairment and psychological distress. Because of the small sample size, we should be careful in interpreting these results. Patients could have improved regardless of the followed treatment. It would increase the impact of our findings if future studies could prove the long-term superiority of CBT over natural course in fatigued cancer survivors. Another reason why it is difficult to draw firm conclusions is that follow-up data were not available of all patients who participated in the previous RCT.

The explorative regression analysis showed a trend that patients with more fatigue, higher psychological distress and stronger somatic attributions at pretreatment were more fatigued at the follow-up assessment. Fatigued cancer survivors have the tendency to attribute their fatigue complaints to the cancer itself and/or cancer treatment (Servaes et al, 2002c). However, research on postcancer fatigue fails to show such relationship, which makes this a false attribution (Servaes et al, 2002b; Hjermstad et al, 2005; Ng et al, 2005; Prue et al, 2006; Young and White, 2006). In the current model of post-cancer fatigue, we assume that fatigue originates in the diagnostic and treatment stage; however, there is no clear relationship between fatigue long after curative treatment and the initial disease and cancer treatment characteristics. Because somatic attributions still proved to contribute to fatigue at follow-up in this study, it seems that this aspect has received not enough attention during the CBT. If a patients continues to think that the cancer itself and/or cancer treatment is responsible for the experienced fatigue, the chance on recovery is lowered. It is possible that (further) education on post-cancer fatigue for professionals working in cancer care can increase the chance of improvement with CBT. Somatic attributions in fatigued cancer survivors can be reinforced by inaccurate information delivery about the cause of post-cancer fatigue. Therefore, education should be aimed particularly on the model of precipitating and perpetuating factors.

Furthermore, indications were found that patients with high psychological distress had a worse treatment outcome. Extreme high scores on the SCL90 total score $(>200)$ are indicative for psychiatric comorbidity (Arindell and Ettema, 1986). Five patients in our sample met this criterion. All five patients remained fatigued after CBT. When deleting these cases, the trend of psychological distress as contributor to fatigue at follow-up disappeared in the regression analysis $(P=0.776)$. Therefore, fatigued cancer survivors with high scores on psychological distress (probably indicative of psychiatric comorbidity) proved to have hardly any chance to improve with CBT for post-cancer fatigue. However, results from the regression analyses should be regarded as exploratory and interpreted with caution.

Most studies on post-cancer fatigue do not find an association between fatigue and cancer type (Servaes et al, 2002b; Prue et al, 2006; Gielissen et al, 2007). In the current study, we did not find a significant difference in fatigue severity at baseline between the different types of cancer $(P=0.821)$. There was also no difference in effect of CBT on fatigue severity $(P=0.983)$. However, our study was limited to patients with rather frequently diagnosed tumours. Therefore, replication is necessary in survivors with other cancer types.

The long-term follow-up results of our study shows that the positive effects of CBT especially designed for post-cancer fatigue are maintained even years after treatment. Until now, no other interventions have been published with comparable good results on post-cancer fatigue on the long term.

\section{ACKNOWLEDGEMENTS}

Current Controlled Trials: ISRCTN: 44562532. Funding for this study was provided by the Dutch Cancer Society (KUN 2001-2378).

\section{REFERENCES}

Aaronson NK, Ahmedzai S, Bergman B, Bullinger M, Cull M, Duez NJ, Filiberti A, Flechtner H, Fleishman SB, de Haes JC, Kaasa S, Klee M, Osoba D, Razav D, Rofe P, Schraub S, Sneeuw K, Sullivan M, Takeda F (1993) The European organization for research and treatment of cancer QLQ-C30: a quality-of-life instrument for use in international clinical trials in oncology. J Natl Cancer Inst 85: 365-376

Arindell WA, Ettema JHM (1986) SCL-90, Handleiding Bij Een Multidimensionele Psychopathologie-Indicator. Swets \& Zwitlinger B.V: Amsterdam Basen-Engquist K, Carmack Taylor CL, Rosenblum C, Smith MA, Shinn EH, Greisinger A, Gregg X, Massey P, Valero V, Rivera E (2006) Randomized pilot test of lifestyle physical activity intervention for breast cancer survivors. Patient Educ Couns 64: 225-234 
Bergner M, Bobbitt RA, Carter WB, Gilson BS (1981) The sickness impact profile. Development and final revision of a health status measure. Med Care 19: 787-805

Beurskens AJHM, Bultman U, Kant IJ, Vercoulen JHMM, Bleijenberg G, Swaen GMH (2000) Fatigue among working people: validity of a questionnaire measure. Occup Environ Med 57: 353-357

Bower JE, Ganz PA, Desmond KA, Bernaards C, Rowland JH, Meyerowitz BE, Belin TR (2006) Fatigue in long-term breast carcinoma survivors. A longitudinal investigation. Cancer 106: $751-758$

Broeckel JA, Jacobsen PB, Horton J, Balducci L, Lyman GH (1998) Characteristics and correlates of fatigue after adjuvant chemotherapy for breast cancer. I Clin Oncol 16: 1689-1696

Brom D, Kleber RJ (1985) De Schok Verwerkings Lijst [the Impact of Event Scale - Dutch adaptation]. Ned Tijdschr Psych 40: 164-168

Courneya KS, Mackey JR, Bell GJ, Jones LW, Field CJ, Fairey AS (2003) Randomized controlled trial of exercise training in postmenopausal breast cancer survivors: cardiopulmonary and quality of life outcomes. J Clin Oncol 21: $1660-1668$

Creamer M, Bell R, Failla S (2003) Psychometric properties of the impact of event scale - revised. Behav Res Ther 41: 1489-1496

Culos-Reed SN, Carlson LE, Daroux LM, Hately-Aldous S (2006) A pilot study of yoga for breast cancer survivors: physical and psychological benefits. Psycho-Oncol 15: $891-897$

Derogatis LR (1994) SCL-90-R: Administration, Scoring and Procedures Manual. 3rdedn.. National Computer Systems: MN, USA

Dittner AJ, Wessley SC, Brown RG (2004) The assessment of fatigue: a practical guide for clinicians and researchers. J Psychosom Res 56: $157-170$

Gielissen MFM, Schattenberg AVM, Verhagen CAHHVM, Rinkes MJ, Bremmers MEJ, Bleijenberg G (2007) Experience of severe fatigue in long-term survivors of stem cell transplantation. Bone Marrow Transpl 39: $595-603$

Gielissen MFM, Verhagen S, Witjes AJ, Bleijenberg G (2006) The effects of cognitive behavior therapy in severely fatigued disease-free cancer patients compared to patients waiting for this treatment. A randomized controlled trial. J Clin Oncol 24: $4882-4887$

Hjermstad SD, Fosså SD, Oldervoll L, Holte H, Jacobsen AB, Loge JH (2005) Fatigue in long-term Hodgkin's disease survivors: A follow-up study. J Clin Oncol 23: 6587-6595

Jacobs HM, Luttik A, Touw-Otten FW, de Melker RA (1990) [the sickness impact profile; results of an evaluation study of the Dutch version] De 'sickness impact profile'; resultaten van een valideringsonderzoek van de Nederlandse Versie. Ned Tijdschr Geneeskd 134: 1950-1954

Molassiotis A, Sylt P, Diggins H (in press) The management of cancerrelated fatigue after chemotherapy with acupuncture and acupressure: a randomised controlled trial. Complement Ther Med

Ng AK, Li S, Recklitis C, Neuberg D, Chakrabartis S, Silver B, Diller L (2005) A comparison between long-term survivors of Hodgkin's disease and their siblings on fatigue level and factors predicting for increased fatigue. Ann Oncol 16: 1949-1955

Pinto BM, Frierson GM, Rabin C, Trunzo JJ, Marcus BH (2005) Homebased physical activity intervention for breast cancer patients. J Clin Oncol 23: $3577-3587$

Prins JB, Bleijenberg G, Bazelmans E, Elving LD, de Boo ThM, Severens JL, van der Wilt G, Spinhoven P, van der Meer JWM (2001) Cognitive behaviour therapy for chronic fatigue syndrome: A multicentre randomised controlled trial. Lancet 357: $841-847$

Prue G, Rankin J, Allen J, Gracey J, Cramp F (2006) Cancer related fatigue: a critical appraisal. Eur J Cancer 42: 846-863

Servaes P, Verhagen C, Bleijenberg G (2002a) Fatigue in cancer patients during and after treatment: prevalence, correlates and interventions. Eur J Cancer 38: $27-43$

Servaes P, Prins J, Verhagen S, Bleijenberg G (2002b) Fatigue after breast cancer and in chronic fatigue syndrome: similarities and differences. J Psychosom Res 52: $453-459$

Servaes P, Verhagen C, Bleijenberg G (2002c) Determinants of chronic fatigue in disease-free breast cancer patients, a cross-sectional study. Ann Oncol 13: 589-598

Servaes P, Verhagen C, Bleijenberg G (in press) the course of severe fatigue in disease-free breast cancer patients: a longitudinal study. Psycho-Oncol

Servaes P, Verhagen C, Schreuder BHW, Veth RPH, Bleijenberg G (2003) Fatigue after treatment for malignant and benign bone and soft tissue tumors. J Pain Symptom Manag 26: 1113-1122

Stulemeijer M, de Jong LWAM, Fiselier TJW, Hoogveld SWB, Bleijenberg G (2005) Cognitive behaviour therapy for adolescents with chronic fatigue syndrome: randomised controlled trial. $\mathrm{Br}$ Med J 330: $7481-7486$

Sugawara Y, Akechi T, Okuyama T, Matsuoka Y, Nakano T, Inagati M, Imoto S, Fujimori M, Hosaka T, Uchitomi Y (2005) Occurrence of fatigue and associated factors in disease-free breast cancer patients without depression. Support Care Cancer 13: 628-636

Van der Ploeg E, Mooren TTM, Kleber RJ, van der Velden PG, Brom D (2004) Construct validation of the dutch version of the impact of event scale. Psych Assess 16: 16-26

van Sonderen E (1993) Sociale Steun Lijst - Interacties (SSL-I) en Sociale Steun Lijst - Discrepanties (SSL-D). Noordelijk Centrum voor Gezondheidsvraagstukken: Groningen

Vercoulen JH, Swanink CM, Galama JM, Fennis JFM, Jongen PJH, Hommes OR, van der Meer JW, Bleijenberg G (1998) The persistence of fatigue in chronic fatigue syndrome and multiple sclerosis: development of a model. J Psychosom Res 45: 507-517

Vercoulen JHHM, Swanink CMA, Fennis JFM, Galama JMD, van der Meer JWM, Bleijenberg G (1994) Dimensional assessment of chronic fatigue syndrome. J Psychosom Res 38: 383-392

Young KE, White CA (2006) The prevalence and moderators of fatigue in people who have been successfully treated for cancer. J Psychosom Res 60: $29-38$

\section{Appendix A}

Table AI Patients were asked to complete questionnaires at the Expert Centre Chronic Fatigue of the Radboud University Nijmegen Medical Centre, pretreatment and post-treatment.

\begin{tabular}{|c|c|c|c|}
\hline Questionnaires & & Response format & Example questions \\
\hline Fatigue severity & $\begin{array}{l}\text { Checklist Individual strength - subscale } \\
\text { Fatigue Severity ( } 8 \text { items) }\end{array}$ & $\begin{array}{l}\text { Seven-point Likert scale } \\
\text { Range } 8-56 \\
\text { A score of } 35 \text { indicates severe fatigue }\end{array}$ & $\begin{array}{l}\text { I feel tired } \\
\text { I am rested } \\
\text { Physically | feel exhausted }\end{array}$ \\
\hline Functional impairment & $\begin{array}{l}\text { SIP-8 } \\
\text { Home management ( } 10 \text { items) } \\
\text { Mobility ( } 10 \text { items) } \\
\text { Alertness behaviour ( } 10 \text { items) } \\
\text { Sleep/rest ( } 7 \text { items) } \\
\text { Ambulation ( } 12 \text { items) } \\
\text { Social interactions ( } 20 \text { items) } \\
\text { Work ( } 8 \text { items) } \\
\text { Recreation and pastimes ( } 8 \text { items) }\end{array}$ & $\begin{array}{l}\text { Patients can mark a box behind each statement. } \\
\text { A total score is calculated by addition the } \\
\text { weights of items } \\
\text { Range } 0-5799\end{array}$ & $\begin{array}{l}\text { I am not doing any of the house cleaning that I } \\
\text { would usually do (hm) } \\
\text { I am not going out to visit people at all (si) } \\
\text { I walk shorter distances or stop to rest often } \\
\text { (amb) } \\
\text { I react slowly to thing that are said (alert) } \\
\text { I have difficulty doing activities involving } \\
\text { concentration and thinking (alert) }\end{array}$ \\
\hline Psychological distress & $\begin{array}{l}\text { Symptom Check List } 90 \text { (90 items) } \\
\text { Anxiety ( } 10 \text { items) } \\
\text { Agoraphobia (7 items) }\end{array}$ & $\begin{array}{l}5 \text { point Likert scale } \\
\text { Range } 90-450\end{array}$ & $\begin{array}{l}\text { During the past } 7 \text { days about how much were } \\
\text { you distressed or bothered by: } \\
\text { Feeling fearful (anx) }\end{array}$ \\
\hline
\end{tabular}


Table AI (Continued)

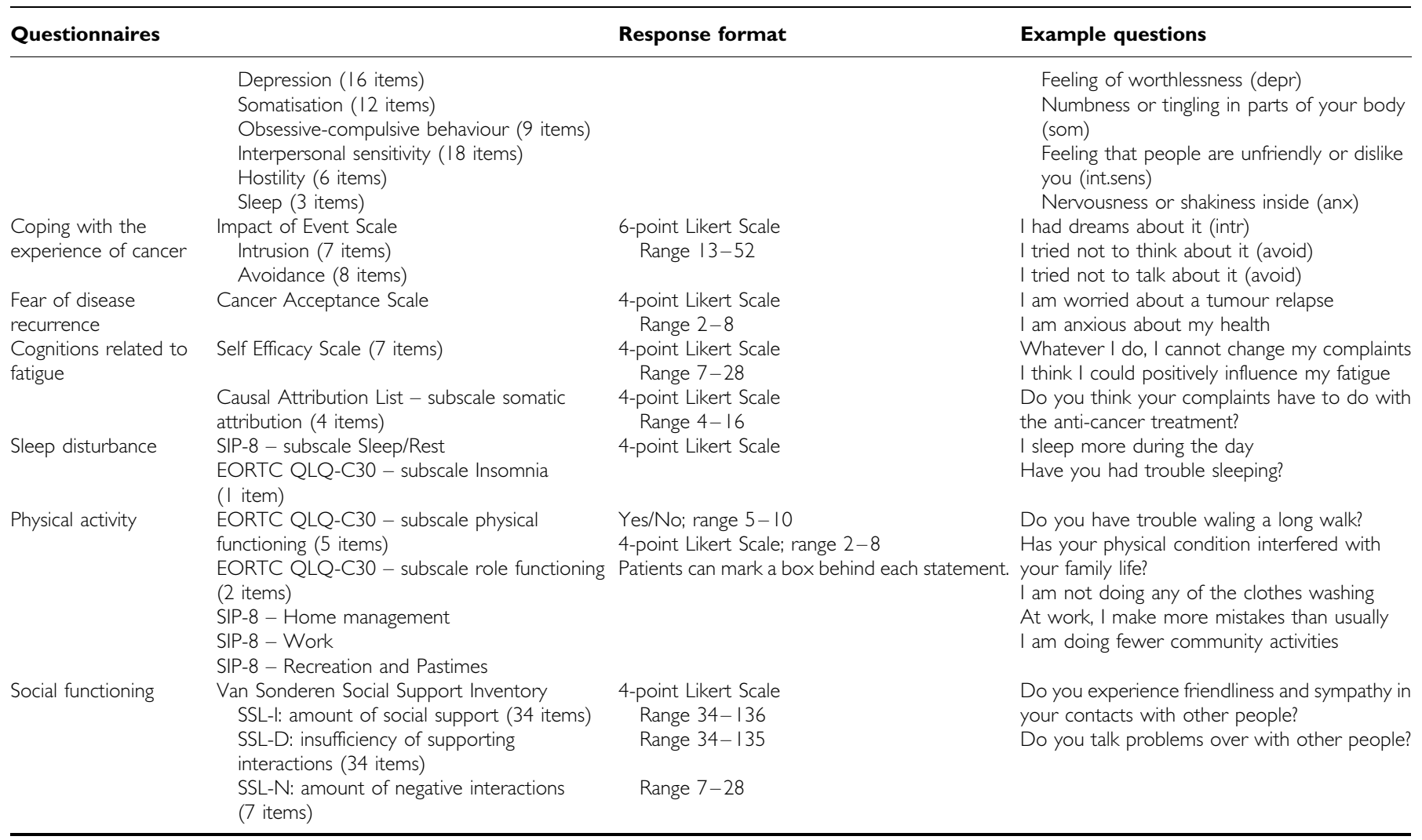

